\title{
UMA POLÍTICA DE CULTURA PARA O BRASIL DE HOJE*
}

\author{
Celso Lafer \\ Professor Titular do Departamento de Filosofia e Teoria Geral do Direito \\ da Faculdade de Direito da Universidade de São Paulo
}

\begin{abstract}
Resumo:
O artigo examina, preliminarmente, antecedentes importantes do liberalismo para explicar a sua vertente contratualista. Expõe a seguir, numa perspectiva "ex parte populi", a importância da política da cultura como uma instituição estratégica de liberdade, uma vez que enseja, em contraste com a política cultural, a liberdade como não-impedimento; a liberdade como participação e a liberdade como "bildung". Discute os princípios da política da cultura (veracidade, publicidade, espírito crítico, probidade) que tem como fundamento o valor tolerância, concluindo com um exame analítico da relevância deste valor para encaminhar dilemas do mundo contemporâneo.
\end{abstract}

\begin{abstract}
:
The article explains relevant characteristics of liberalism so as to give a view of its neo-contractualism dimension. Then, on the basis of an "ex parte populi" perspective, the article sustains the relevance of a politics of culture as a strategic institution of liberty since it offers the opportunity for positive-liberty, negative-liberty and liberty as "bildung" The principle of a politics of culture (thruthfulness, publicity, critical spirit, honesty) are discussed having as an axiological foundation the value of "tolerance", a most relevant value to enable us to deal with the dilemma of the contemporary world.
\end{abstract}

1. O teiria e as suas razões.

O líbcralismo está na ordem do dia, com a derrocada da experiência soviética que colocou em questão os caminhos do socialismo.

Esta "vitória" do liberalismo vem simplificando de maneira inadequada o debate intelectual, que se politiza na forma de um catecismo liberal, da mesma maneira que o catecismo marxista simplificava a discussão quando era culturalmente hegemônico.

* São Paulo, 15 de outubro de 1992. 
O liberalismo é mais rico e complexo que o seu catecismo e, ao contrário da tradição socialista que misoneisticamente se estruturou em torno de um só clássico - Marx - tem, neste sentido, o mérito de ser pluralista desde as suas origens e o que perde em foco ganha em abrangência. Caracteriza-se, assim, por uma multiplicidade de clássicos. Kant e Adam Smith, Humboldt e Tocqueville, Benjamin Constant e John Stuart Mill, por exemplo, se têm afinidades relevantes que permitem integrá-los na família dos patronos da doutrina liberal, assinalam-se por diferenças muito apreciáveis.

Esta variedade persiste até hoje. Por isso convém falar em liberalismos no plural e não em liberalismo no singular, pois uma só etiqueta uniformizadora não apenas não permite captar as diferenças que separam um Hayek de um Bobbio, um Raymond Aron de um John Rawls, um Octavio Paz de um Popper, um Dahrendorf de um Isaiah Berlin, como também não permite sublinhar que a doutrina liberal contém tanto vertentes de vocação conservadora quanto vertentes de índole inovadora e radical.

Neste texto vou discutir e analisar "valores" da doutrina liberal que colocam uma visão do papel e do problema da cultura em relação ao estado, à sociedade e ao direito. Considero este tema relevante no âmbito da Universidade - que ex officio trata da cultura - e muito especialmente na nossa Faculdade uma vez que o Direito é um fenômeno cultural - é um construído pelos homens e não um dado da natureza caracterizando-se como um bem cultural, que tem, como ensina Miguel Reale, dois elementos, um suporte e um significado. Se o suporte do Direito hoje é o direito positivo, o seu significado está ligado a valores que cabe compreender e justificar uma tarefa que incumbe ao professor de Filosofia do Direito, que sou nesta casa, empreender. ${ }^{1}$

\section{Preliminares.}

Inicio com um arrolamento dos antecedentes, observando que historicamente o liberalismo inseriu na agenda política a demarcação nítida entre estado/e não estado. Com ele (i) o estado perdeu o monopólio do poder

1. Cf. Miguel Reale, Filosofia do direito, $10^{\mathrm{a}}$ ed., São Paulo, Saraiva, 1983, parágrafos 91, 94, 95,100 . 
ideológico com reconhecimento do direito à liberdade religiosa e à liberdade de opinião e de pensamento.

Daí a relação entre liberalismo e laicismo e liberalismo e tolerância no sentido positivo que se contrapõe ao fanatismo ao se aceitar que a verdade não é una mas múltipla e tem várias faces.

Com ele também (ii) o estado perdeu o monopólio do poder econômico com o reconhecimento do direito à liberdade econômica.

Esta demarcação nítida entre estado e não estado, como observa Bobbio, deriva da diferenciação conceitual entre o político e o social. Ela data do século XIX e marca uma ruptura com a tradição do pensamento político de Aristóteles a Hegel - compartilhada por isso mesmo tanto pela tradição liberal quanto pela socialista ao colocar como pressuposto que o Estado é parte do qual a sociedade é um todo. ${ }^{2}$

Mais especificamente, o estado é o aparato coercitivo da sociedade por isso deve ser mínimo (liberalismo) ou desaparecer (socialismo).

$\mathrm{Na}$ tradição liberal, o estado como o aparato coercitivo da sociedade deve ser balizado por normas jurídicas é o princípio da legalidade inerente ao estado de direito que se exprime através de imperativos impessoais. Estes evitam o personalismo do arbítrio pessoal dos governantes, e buscam fazer do monopólio estatal de coerçâo organizada força e não violência. Com efeito, se esta tem como notas a imprevisibilidade, a descontinuidade e a desproporção entre meios e fins, aquela tem como característica a medida dada pela norma que impõe o agir com medida, de acordo com a medida, e com o objetivo de alcançar a medida. ${ }^{3}$

Esta preocupação com a medida é uma forma de domesticar o poder. Deriva da mudança trazida pelo tema dos direitos humanos colocado pela tradição liberal, que inaugurou juridicamente a perspectiva dos governados ao reconhecer que estes têm direitos e não apenas deveres impostos pelos governantes. Em outras palavras, o estado é para o indivíduo e não o indivíduo é

2. Cf. Norberto Bobbio, Estado, governo, sociedade, Rio de Janeiro, Paz e Terra, 1987, p. 6162.

3. Cf. Norberto Bobbio, Il terzo assente, Milano, Sonda, 1989, p. 151. 
para o estado como explica Bobbio na sua exegese do art. $2^{\circ}$ da Declaração Francesa dos Direitos do Homem e do Cidadão. ${ }^{4}$

Isto quer dizer que o direito não é encarado na perspectiva do soberano que coloca os deveres para os seus súditos, mas sim na perspectiva dos governados visto como cidadãos, que têm, para usar a formulação de Hannah Arendt, $o$ direito a ter direitos. 5

Observo que ao colocar a questão nestes termos - o dos direitos da cidadania, estou me filiando a uma vertente contratualista do liberalismo, de cunho jurídico e inspiração republicana, e não a uma vertente utilitarista de cunho econômico. Com efeito, na perspectiva contratualista, como aponta Salvatore Veca, a legitimação da mão visível da autoridade pública encontra-se na sua capacidade de tutelar direitos dos cidadãos, tendo em vista o acesso e a geração de oportunidades para que cada indivíduo possa afirmar pela livre escolha de fins no tempo a sua identidade. Não é isso o que ocorre na perspectiva utilitarista, para a qual a legitimação da mão visível da autoridade é a eficiência dos resultados no atendimento dos interesses agregados da sociedade, buscando, na fórmula de Bentham, trazer a maior felicidade para o maior número, e no qual se considera o indivíduo que integra este número apenas como maximizador de seus interesses e preferências. ${ }^{6}$

É por esse motivo, aliás, que existe um conflito latente entre juristas e economistas, pois os juristas tendem, pela sua própria formação, a defender uma ética de princípios a dos direitos e os economistas, também pela sua própria formação, a afirmar uma ética de resultados, para a qual os direitos não são uma questão em si, mas são redefinidos em termos de utilidade. É isto, diga-se de passagem, que está na raiz dos conflitos entre os juristas e os formuladores da política econômica no Brasil dos últimos anos.

4. Cf. Norberto Bobbio, Estado... ob. cit., p. 117; A era dos direitos, Rio de Janeiro, Campus, 1992, p. 49-65, 85-111.

5. Hannah Arendt, Origens do totalitarismo, São Paulo, Cia. das Letras, 1989, p. 300-336; Celso Lafer, A reconstrução dos direitos humanos, São Paulo, Cia. das Letras, 1988, cap. 5.

6. Cf. Salvatore Veca, Questioni di giustizia, Parmá. Pratiche, 1985, p. 69-81. 


\section{Apresentação do tema.}

O tema da cultura na visão da doutrina liberal - pede uma referência analítica do termo política, que comporta polaridades. Entre elas a que contrapõe a política domínio e a política programa-de-ação. ${ }^{7}$

A dimensão política domínio surge através da interferência decisória do poder no exercício de uma função hierárquica de gestão da sociedade para determinar uma opção entre múltiplos possíveis e não necessariamente compatíveis programas-de-ação.

Na perspectiva liberal, em matéria de cultura, o que se pretende é excluir a cultura da política-domínio, para impedir que o Estado recupere o monopólio do poder ideológico. Este tema mantém a sua atualidade de um lado com a exacerbação dos "fundamentalismos" que está ocorrendo no mundo (por exemplo: Oriente Médio) e que não é capaz de lidar com a compatibilidade de verdades contrapostas; de outro com a nova problemática da tolerância que hoje, além de ter que lidar com a diversidade de crenças e opiniões, precisa discutir o tema da convivência de diversidades de outra natureza, como as de línguas, raças, etnias e nacionalidades, onde o diferente provoca a discriminação e a intolerância dos preconceitos ${ }^{8}$ e pode levar à guerra civil e à centrifugação e à secessão de estados (como, por exemplo, no Leste Europeu e na antiga URSS).

Dito isso, vou iniciar a apresentação do tema por meio de uma dicotomia proposta por Norberto Bobbio que contrasta, diferenciando a política da cultura da política cultural.

i. Política cultural é a planificação e a organização da cultura em função de interesses políticos. Representa a idéia de uma cultura policiada no plano do estado pela censura e no da sociedade pelo "patrulhamento ideológico" com vistas ao domínio hegemônico de uma única e monista visão do estado, da sociedade e do direito.

ii. Política da cultura representa a política dos homens de cultura na defesa das condições da existência e do desenvolvimento da cultura. Neste

7. Cf. Raymond Aron, Democracia e totalitarismo, Lisboa, Presença, 1966, p. 21-35; Celso Lafer, O sistema político brasileiro, São Paulo, Perspectiva, 1975, parte 1.

8. Cf. Norberto Bobbio, A era... ob. cit., p. 203-204. 
sentido ela é, politicamente, um programa-de-ação e não uma proposta de domínio. ${ }^{9}$

Observo que, se a visão liberal do papel da cultura, que estou buscando justificar, é contrária à cultura instrumentalmente policiada por interesses políticos, isto não significa a defesa de uma cultura apolítica, separada da sociedade na qual vive, e dos problemas desta sociedade, ou seja, uma cultura não empenhada e indiferente e que não se comunica com a esfera dos interesses sociais.

O liberalismo se opõe a uma cultura policiada mas não quer uma cultura apolítica pois pressupõe um nexo na relação entre política e cultura. Este nexo é dado pelo valor tolerância - que adiante examinarei - que requer a democracia como o solo no qual se fertiliza a cultura como livre racionalidade crítica. Tolerância, adianto, na minha perspectiva, não significa indiferença, indulgência, ou falta de princípios, mas sim a tutela da política da cultura como condição de um regime democrático. ${ }^{10}$

4. Qual é o fundamento político da cultura?

A resposta a esta pergunta, para a visão liberal, é inequívoca: $a$ política da cultura é uma instituição estratégica da liberdade - aspiração unificadora do liberalismo.

Responde, assim, à multiplicidade das dimensões de liberdade, das quais vou destacar três, neste texto: a liberdade como não-impedimento; a liberdade como participação e a liberdade como "bildung".

$i$. A liberdade como não-impedimento, que é a assim chamada desde Benjamin Constant, liberdade moderna ou liberdade-negativa como a qualifica Isaiah Berlin, traduz-se na "freedom-from" na liberdade da opressão e da coerção.

A política da cultura tutela a liberdade como não-impedimento ao postular uma cultura livre, ou seja, uma cultura não impedida por obstáculos materiais que dificultam a livre circulação e troca de idéias, ou por obstáculos

9. Cf. Norberto Bobbio, Política e cultura, Torino, Einaudi, 1977, p. 37.

10. Ibid., p. 34-35. 
psíquicos e morais que resultam da pressão de vários tipos sobre as consciências e mentes da cidadania. ${ }^{11}$

ii. A liberdade como participação, que é a assim chamada liberdade dos antigos, ou liberdade positiva, representa a "freedom to" - a ampliação de oportunidades de participação coletiva da cidadania na criação e divulgação dos bens culturais. A política da cultura a tutela na exata medida em que não é domínio e imposição, mas sim um programa-de-ação múltiplo a ser exercido pela vontade autônoma dos indivíduos no uso dos seus direitos de cidadania.

No primeiro caso - a liberdade como não-impedimento a política da cultura tutela a liberdade permitindo que o indivíduo, considerado como um todo em si mesmo, seja livre para criar e fruir; no segundo caso - a liberdade como participação a política da cultura tutela a liberdade, assegurando que o indivíduo, considerado como parte de um todo a comunidade política seja livre para participar democraticamente e com autonomia da cultura e não por força da imposição dos governantes, de cima para baixo. ${ }^{12}$

Liberdade como não-impedimento e liberdade como participação são complementares, como anota J. G. Merquior, ${ }^{13}$ pois têm em comum a idéia de autodeterminação - o que me leva a discutir a terceira dimensão de liberdade, a

iii. liberdade como "bildung", ou seja, como o desabrochar do potencial humano através da autônoma construção e amadurecimento da personalidade de cada indivíduo. Esta dimensão da liberdade, que foi articulada com inspiração goetheana por von Humboldt, no seu clássico ensaio sobre os limites da ação do estado e retomado por Stuart Mill em On liberty, é inerente à doutrina liberal, que coloca em evidência não aquilo que os homens têm em comum enquanto homens, mas aquilo que têm de diverso enquanto indivíduos.

11. Cf. Norberto Bobbio, Política... ob. cit., p. 38.

12. Cf. Norberto Bobbio, Ensaios escolhidos, São Paulo, Ch. Cardim, s.d., p. 23.

13. José Guilherme Merquior, $O$ liberalismo: antigo e moderno, Rio de Janeiro, Nova Fronteira, 1991, p. 21-27. 
Por isso o liberalismo tutela a individualidade enquanto diversidade, vendo no pluralismo um dos elementos do bem-estar no mundo.

A liberdade como diversidade, para ensejar o "bildung", faz da cultura um "bem incompressível" que responde às necessidades profundas dos homens. É por isso, como observa Antonio Candido, que a literatura é um direito humano fundamental, pois leva à formação do homem, na medida em que, como imagem e transfiguração da própria vida, traz livremente em si o que chamamos o bem e o mal proscrito e o sancionado organizando e humanizando de múltiplas maneiras a aventura da vida. ${ }^{14}$

A política da cultura tutela a possibilidade da liberdade como "bildung" precisamente porque parte do pressuposto de que o pluralismo e a diversidade são um bem incompressível a ser assegurado à cidadania.

Recapitulando, na perspectiva "ex parte populi" e, portanto, na linguagem dos direitos, o que foi dito sobre o fundamento da política da cultura para o liberalismo:

a. Os direitos-garantia de primeira geração, como os da liberdade de religião, pensamento, opinião, ao assegurar a amplitude do lícito, ensejam a liberdade como não-impedimento.

b. Os direitos humanos de segunda geração, ao colocarem os créditos do indivíduo em relação à coletividade através dos temas dos direitos econômico-sociais e culturais, postulam maiores oportunidades para a liberdade como participação, buscando criar a igualdade dos pontos-de-partida, inclusive para a fruição da liberdade como não-impedimento.

Realço aqui a relevância dos direitos de segunda geração, posto que neles se encontra a chave da relação entre liberdade e igualdade para a visão liberal que não é a do igualitarismo que considera desejável que todos sejam iguais em tudo, mas sim a de que se amplie a igualdade de oportunidades para que todos possam livremente buscar uma identidade diferenciada. ${ }^{15}$

14. Cf. Antonio Candido, Direitos humanos e literatura, in A. C. Ribeiro Fester (org.), Direitos humanos e, São Paulo, Brasiliense, 1989, p. 107-126.

15. Cf. Norberto Bobbio, in Bobbio et alii, Equalianza e equalitarismo, Roma, Armando, 1978 , p. 13-25. 
Não preciso dizer que há uma infinidade de coisas a fazer num país como o nosso, com pouca memória de sua cultura, que não preserva adequadamente sequer a memória histórica das elites e que, dadas as condições de pobreza e marginalidade, o passado da cultura tende a ser, para a maioria da população como observa Hélio Jaguaribe -, apenas a herança da língua e da miséria. A primeira evidentemente é a de ocupar-se com a educaçāo, pois sem educação cada geração começa do zero, sem tirar proveito da experiência das gerações anteriores, obstaculando, assim, o clássico papel da cultura como cultivo como cultura animi - tão necessária para o juízo apropriado da cidadania na condução da res publica e do indivíduo na orientação de sua vida privada. ${ }^{16}$

c. A tutela do "freedom from" e do "freedom to" a da liberdade tanto como exercício quanto como oportunidade - é a condição da possibilidade da liberdade como "bildung" diferenciada, base de uma sociedade e de uma cultura pluralista, aberta à diversidade - um valor-chave do liberalismo cuja realizabilidade a política da cultura enseja.

5. Princípios da política da cultura.

A política da cultura, sendo a política dos homens de cultura na defesa das condições de existência e do desenvolvimento da cultura obedece a certos princípios. Estes princípios vou qualificar como princípios gerais, fazendo assim uma analogia com os princípios gerais do direito, pois à semelhança destes, têm uma função como critério diretivo na interpretação e como critério programático no progresso da cultura. Penso que cabe dar a eles o devido destaque no âmbito da Universidade, posto que representam o núcleo da ética da política da cultura que é indispensável explicar e justificar numa aula inaugural de abertura dos cursos jurídicos.

i. O primeiro princípio da política da cultura é o empenho na busca da verdade, o que se traduz na afirmação do princípio da veracidade.

16. Cf. Hélio Jaguaribe, Alternativas do Brasil, Rio de Janeiro, José Olímpio, 1989, p. 66; Hannah Arendt, Entre o passado e o futuro, São Paulo, Perspectiva, 1972, cap. 6. 
Isto significa não falsificar os fatos e não torcer os argumentos, oferecendo tenaz resistência à tentação da mentira e do engano.

A publicidade como critério de moral como ensina Kant - e a boa-fé na discussão como mostra Stuart Mill - são ingredientes asseguradores do princípio da veracidade, e não preciso indicar a importância mais ampla disso. Basta pensar, no âmbito da sociedade, como este princípio é válido na análise do que deve ser e freqüentemente não é, o papel dos meios de comunicação a saber: o de oferecer à cidadania uma informação exata e honesta, para que a voz da razão possa manifestar-se.

ii. O segundo princípio da política da cultura é o espírito crítico, vale dizer, não querer transformar a ciência em sapiência profética, empreender uma constante crítica dos pressupostos, pensar o significado daquilo que se conhece. Esta é, por excelência, no meu modo de ver, a tarefa da Filosofia do Direito no campo jurídico, pois sendo o direito um bem cultural, cabe a esta disciplina descortinar o significado do direito positivo. Isto se faz através do "aut-aut" do diálogo, inerente ao pluralismo que nutre a visão liberal da realidade, não do "et$e t$ " do dogmatismo impositivo que gera sistemas fechados à discussão.

iii. O terceiro princípio da política da cultura é o dever da probidade.

Este dever se traduz em método e rigor no trabalho intelectual; na circunspeç̧ão que deve preceder o julgar e a tomada de posição, o que se faz controlando e examinando todos os argumentos antes de pronunciar-se, sendo preferível renunciar a pronunciar-se do que fazê-lo açodada e precariamente.

Estes princípios que estou extraindo da reflexão de Bobbio $^{17}$ têm como base o tema da tolerância, que vou examinar como arremate desta exposição.

6. A tolerância e a política da cultura.

O liberalismo, ao postular uma política da cultura encarado como um programa-de-ação, e ao rejeitar uma política cultural baseada na imposição do domínio do poder, tem como fundamento o valor tolerância.

17. Cf. Norberto Bobbio, Política... ob. cit., p. 39-43. 
$i$. Este pode ser defendido e justificado preliminarmente em termos de razāo prática.

Com efeito, a tolerância não quer dizer ceticismo ou indiferença. Quer dizer, na visão liberal, que a verdade não pode triunfar pela imposição ou pela perseguição, pois a democracia parte do pressuposto de que a convivência coletiva requer a civilidade do princípio de reciprocidade - o "do ut des" da tolerância mútua pois se me atribuo o direito de impor e perseguir, concedo ao outro este mesmo direito. Neste primeiro plano, como observa Bobbio, a tolerância se fundamenta em razões práticas da prudência política - é um cálculo para assegurar a aposta da convivência pacífica.

Esta aposta tem a sustentá-la, num segundo plano mais profundo, a confiança na razão e na razoabilidade do Outro, ou seja, na viabilidade da persuasāo como método de discussão da verdade e no equívoco da imposição coercitiva.

Como dizia Morus em $A$ utopia "não é pela controvérsia travada com as armas na mão mas pela suavidade e pela razão - que a verdade se liberta por si própria, luminosa e triunfante, da treva do erro". ${ }^{18}$

$\mathrm{Na}$ mesma linha afirmaria Locke, na sua clássica Letter concerning toleration, que, não só a verdade não é ensinada pelas leis nem necessita da força para obter a sua entrada na mente dos homens como se torna mais fraca valendo-se da violência. ${ }^{19}$

Como é sabido, confiar nos métodos da persuasão e não nas técnicas da força, como meio de solucionar as controvérsias, é um ingrediente da democracia, que opta, como lembra Bobbio, "por contar cabeças e não por cortar cabeças".

Além das razões de método, num nível ainda mais profundo que pode ser kantianamente colocado em termos de razão prática, a tolerância justifica-se no plano moral pelo respeito devido à pessoa do outro. Ela é, portanto, não apenas política e socialmente desejável e metodicamente válida do ponto de vista de um regime democrático, mas é igualmente devida numa

18. Cf. Tomás Morus, $A$ utopia, Lisboa, Guimarães, s.d., p. 184.

19. John Locke, A letter concerning toleration, in Locke, Berkeley, Hume, Chicago, Encyclopaedia Brittanica Inc., 1952, p. 15. 
perspectiva ética, pelo respeito inerente ao reconhecimento do outro que caracteriza a visão do mundo da democracia, enquanto desdobramento do liberalismo.

ii. A estes argumentos da razão prática, em prol da tolerância, cabe adicionar, como faz Bobbio, um fundamento que se localiza no plano da razão teórica e que traduz o ponto de vista liberal sobre a própria natureza da verdade. Esta não é una, mas múltipla, dada a complexidade ontológica da realidade. Não vivemos num universo mas sim num multiverso pluralista a que só podemos ter acesso, por aproximações sucessivas, através da política da cultura. ${ }^{20}$

O pluralismo da razão teórica inerente a esta percepção liberal da realidade não significa relativismo nem se traduz em ceticismo.

"Eu prefiro café, você prefere champanhe. Temos gostos diferentes. Não há mais nada a dizer" - isto é relativismo, aponta Isaiah Berlin que sublinha que o pluralismo é algo completamente diferente. Trata-se de uma concepção que se baseia na idéia de que existem "muitos fins diferentes que podem ser buscados pelos homens, fazendo com que estes se sintam plenamente racionais, plenamente realizados, capazes de entendimento, compreensão e iluminação mútuas da mesma forma que nos iluminamos com a leitura de Platão ou os romances do Japão medieval - mundos e concepçóes muito distintos dos nossos".

$\mathrm{O}$ que torna a intercomunicação dos pontos de vista e das culturas no tempo e no espaço possível, continua Berlin, é o fato de que "o que faz os homens seres humanos é algo comum a todos" e é isto que funciona como pontes, estabelecendo pontos de interação. ${ }^{21}$

Num mundo como o nosso, onde a tolerância hoje também diz respeito ao diferente e não apenas ao diverso - inclusive em nosso país onde começam a aflorar tendências centrífugas o reconhecimento da natureza heterogênea da sociedade é o caminho para a integração e o antídoto à desintegração.

Este caminho requer a política da cultura. Juridicamente isto se traduz em reduzir ao mínimo indispensável à ordem pública, os comandos e as

20. Cf. Norberto Bobbio, A era... ob. cit., p. 203-210.

21. Cf. Isaiah Berlin, Limites da utopia, Sāo Paulo, Cia. das Letras, 1991, p. 21. 
proibições por exemplo, os necessários para a preservação do patrimônio histórico-cultural e ampliar ao máximo os estímulos e desestímulos - os incentivos - a ação cultural - que abrem o campo da autonomia da vontade.

Com efeito, sendo a política da cultura uma vis directiva a ser estimulada no âmbito da sociedade, a escolha dos seus meios nela deve brotar, cabendo ao estado não impor mas reconhecer na coordenação da res publica a multiplicidade dos modelos jurídicos por meio dos quais pode se exprimir e articular a política da cultura.

Esta proposta de uma política da cultura tem a sustentá-la uma atitude. Esta não é, como já disse, a acepção negativa da tolerância ou seja: a condescendência indulgente com a falta de princípios, fruto da indiferença e do ceticismo que freqüentemente ocorre nas democracias, assim como a carência de tolerância positiva normalmente acomete as sociedades autoritárias.

Esta atitude requer uma razão aberta porém combativa e combatente, posto que empenhada no inconformismo que anima a minha visão do liberalismo que não aceita o excesso de tolerância negativa e de intolerância negativa, infelizmente tão presentes na experiência brasileira. A militância do liberalismo de inovação, ao qual me filio, não olha as coisas do alto de uma sabedoria ossificada num catecismo. Examina os problemas concretos, seguindo com rigor as lições, ainda que incertas, da experiência histórica, e em conformidade com as verdades parciais que vai recolhendo pelo método das aproximações sucessivas. Participa, assim, como ensina Raymond Aron, da construção prometéica do destino humano, posto que tem, nas palavras de Tocqueville, aquela preocupação salutar com o futuro, que faz velar e combater. $^{22}$

22. Cf. Raymond Aron, De la condition historique du sociologue, Paris, Gallimard, 1971, p. 6464; Norberto Bobbio, Política... ob. cit., p. 205. 